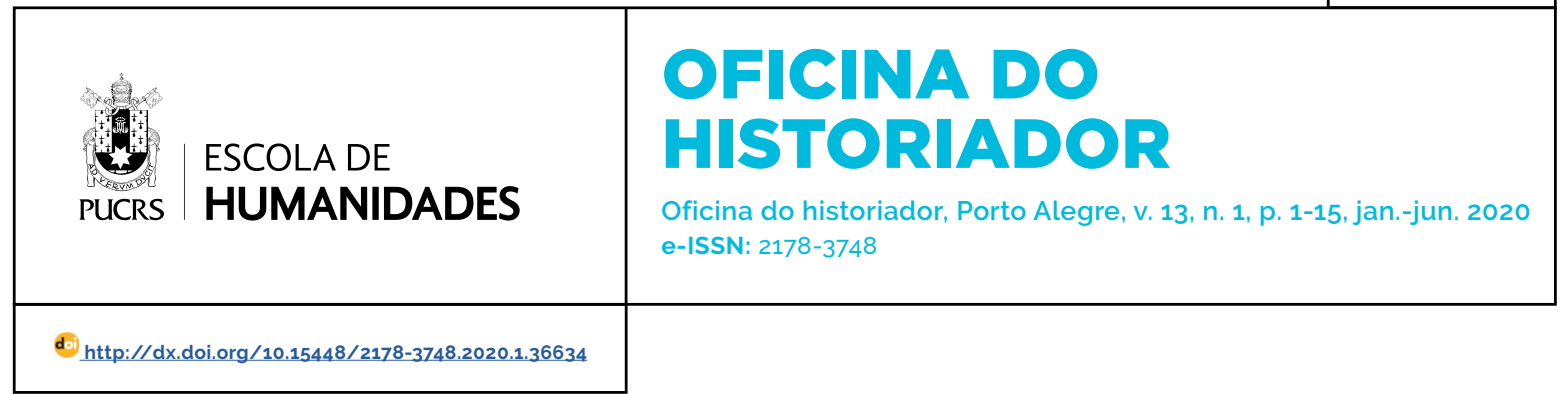

SEÇÃO: DOSSIÊ ARQUEOLOGIA

\title{
Quem faz Arqueologia abre uma janela
}

\author{
Who does Archaeology opens a window
}

\section{Felipe Benites \\ Tramasoli ${ }^{1}$}

orcid.org/0000-0002-6550-1215

felipe@tramasoli.com

Recebido em: 10 dez. 2019 . Aprovado em: 20 jan. 2020. Publicado em: 14 jun. 2020.

\section{(c) (i)}

Artigo está licenciado sob forma de uma licença Creative Commons Atribuição 4.0 Internacional.
Resumo: O pensamento arqueológico tem passado por efervescente criticismo nas últimas décadas em decorrência de ideias que contestam a hegemonia de categorias modernas. A dualidade humanista, a preponderância da discursividade, além da noção de tempo linear são alguns exemplos de categorias que estão em xeque desde o final do século passado. Esse cenário acabou propiciando uma aproximação mais pertinente entre a Arqueologia e outras áreas, como é o caso da Arte. Neste artigo, então, faço uma análise dessa interação, destacando algumas ressalvas que devemos tomar diante desse diálogo. Ainda, defendo que a Arqueologia deva, sim, utilizar-se da Arte, mas não como mera inspiração, tal qual uma nova espécie de Arqueologia promovedora de analogias, mas como um instrumental capaz de nos municiar de uma epistemologia mais combativa, mais condizente com as características próprias do fazer arqueológico. Por fim, trago aqui exemplos de três trabalhos desenvolvidos nos últimos anos e que julgo ilustrarem tal potencialidade.

Palavras-chave: Arqueologia. Arte. Epistemologia.

Abstract: Archaeological thinking has undergone effervescent criticism in recent decades as a result of ideas that challenge the hegemony of modern categories. The humanistic duality, the preponderance of discursiveness, and the notion of linear time, are some examples of categories that have been in check since the end of the last century. This scenario ended up providing a more pertinent approach between Archeology and other areas, such as Art. In this article, then, I provide an analysis of this interaction, highlighting some caveats that we should take before this dialogue. Still, I argue that Archeology should use Art, but not as mere inspiration, as a new kind of Archeology that promotes analogies, but as an instrument capable of providing us with a more combative epistemology, more in keeping with the proper characteristics of archaeological making. Finally, I bring here examples of three works developed in recent years that I think illustrate this potentiality.

Keywords: Archaeology. Art. Epistemology.

\section{Introdução}

Problematizar as próprias condições da produção do conhecimento é uma matéria ontológica seguindo a proposta de Bhaskar de que "qualquer teoria do conhecimento pressupõe uma ontologia sobre como o mundo deve ser para o conhecimento, sob as descrições dadas por uma teoria, para ser possivel" (BHASKAR, 2006, p. 442). Nesse sentido, o que venho a abordar neste artigo é de que forma as mais recentes discussões no campo da Arqueologia podem impactar no entendimento do nosso objeto, da nossa relação com ele e nas possibilidades de práticas que essas discussões incorrem.

Com isso, não pretendo aqui desenvolver uma espécie de revisão sobre os temas que têm sido levantados em oposição às tradições mais consolidadas da disciplina - especificamente àquelas que derivam 
do "novo materialismo", das contestações da ideologia temporal moderna -, mas, sim, partir desse cenário para explorar um aspecto que tem despontado, talvez, como a contribuição mais original e pertinente decorrente da abertura oferecida por essas discussões. Aqui, me refiro à ampliação da aplicabilidade da Arqueologia, tanto no que diz respeito a uma espécie de refúgio às limitações que a discursividade acadêmica implica a uma ciência dedicada a explorar o mundo lá fora, quanto à possibilidade de articulação de um conhecimento produzido pela academia às comunidades a quem essa produção é pertinente.

Sendo assim, começo este artigo explorando a inserção da Arqueologia em um movimento mais recente - o da virada criativa - e, na sequência, sugiro como uma aproximação entre nossa disciplina e, especificamente, a Arte oferece uma oportunidade para elaborarmos uma epistemologia que seja combativa em duplo sentido - no nível da teoria e da prática -, além de, por fim, oferecer alguns exemplos de trabalho que entendo se enquadrarem nesta linha de desenvolvimento.

\section{Antes, algumas considerações sobre a criatividade}

Na última década, tem sido crescente a discussão sobre o impacto de uma recente virada criativa na Arqueologia - embora, devase ressaltar, esse movimento não configura uma especificidade nossa (THOMAS et al., 2017, p. 123) -, que consiste na crescente interação entre arqueólogos e o mundo da Arte, com o objetivo de extrapolar algumas de nossas limitações. No entanto, antes de eu adentrar essa questão, que é central neste artigo, cabe fazer uma consideração sobre a tal criatividade.

Correntemente, tomamos Arte e criatividade como sinônimos. O próprio modo como temos nos referimos a tal aproximação - virada criativa - demonstra isso. Ademais, é pertinente sugerir que não incorreria em prejuizo ao entendimento geral se descrevêssemos tal movimento como virada artística, já que é, fundamentalmente, essa a aproximação substancial. No entanto, entendo ser leviano e potencialmente perigoso assumirmos com naturalidade que a associação entre Arte e criatividade é fundamental ao ponto de tornar essa característica como peculiar e exclusiva a essa prática. Afinal, o âmago da Arte reside em todos nós, pois, se somos capazes de apreciar algo artístico, não teriamos em nós uma qualidade dita artística? Talvez possamos argumentar, de forma semelhante à sugestão de Picasso $^{2}$, de que a questão, nesse sentido, não seria possuirmos ou não uma qualidade artística, mas, sim, trabalharmos em prol da manutenção de tal sensibilidade, que é congênita.

De qualquer forma, o ponto que desejo trazer neste momento é o de que atribuir a primazia da criatividade à Arte é prejudicial, especialmente quando enfatizamos o contexto da relação entre ela com as ciências de forma geral, pois implica diretamente em assumir que (1) a criatividade não é uma caracteristica fundamental da prática científica, uma noção que, indiretamente, (2) concorre para a desumanização da prática científica. Contestar isso, portanto, significa expor nosso telhado de vidro; aceitar que o conhecimento científico não se funda sobre dogmas, mas pelo uso do pensamento humano, original e criativo, que consiste na busca de solução para problemas; compreender que a produção do conhecimento não se justifica por si só, mas que cumpre uma função social; responsabilizarmo-nos pelos desdobramentos dos empreendimentos científicos, que não são moralmente neutros. ${ }^{3}$

Aqui, a questão da ausência ou não da criatividade como qualidade intrínseca ao fazer científico me parece a mais interessante. Pois, não somente a articulação de ideias carece de tal qualidade para a sua maior efetividade, como a própria elaboração

\footnotetext{
2 Me refiro à seguinte afirmação: "Toda criança é um artista. O problema é como permanecer um artista depois que ela cresce". Há uma certa insegurança quanto à autoria da frase. No entanto, ela foi atribuida a Picasso na matéria "Modern Living: Ozmosis in Central Park", publicada na revista Time de 4 de outubro de 1976, que está parcialmente disponivel online. Disponivel em: http://content.time.com/ time/magazine/article/0,9171,918412,00.html. Acesso em: 22 out. 2019.

3 Talvez o exemplo mais extremo e, por isso mesmo, satisfatório, seja papel desempenhado pela física nuclear no segundo quartel do século XX (ISAACSON, 2007, p. 481-488), que, ao mesmo tempo em que oferece oportunidades muito positivas a partir de uma eximia fonte de energia, municiou a humanidade com um artefato capaz de gerar a sua própria extinção.
} 
dos conceitos e suas aplicabilidades. Podemos, ainda, especificamente no nosso caso, estipular em que medida a Arqueologia não é uma ciência naturalmente criativa quando boa parte das suas atividades depende da nossa capacidade de abstrair condições presentes - que podemos caracterizar, talvez, como vestigiais - de modo a gerarmos um entendimento compreensivel sobre sua condição pretérita. E a criatividade não é uma qualidade única às ciências sociais, humanas, mas a todas as ciências, ou alguém seria capaz de dizer que o modo como os físicos e os químicos interpretam o mundo (Figura 1) não carece, também, de muita criatividade?

Figura 1 - This is how scientists see the world [É assim que os cientistas enxergam o mundo]

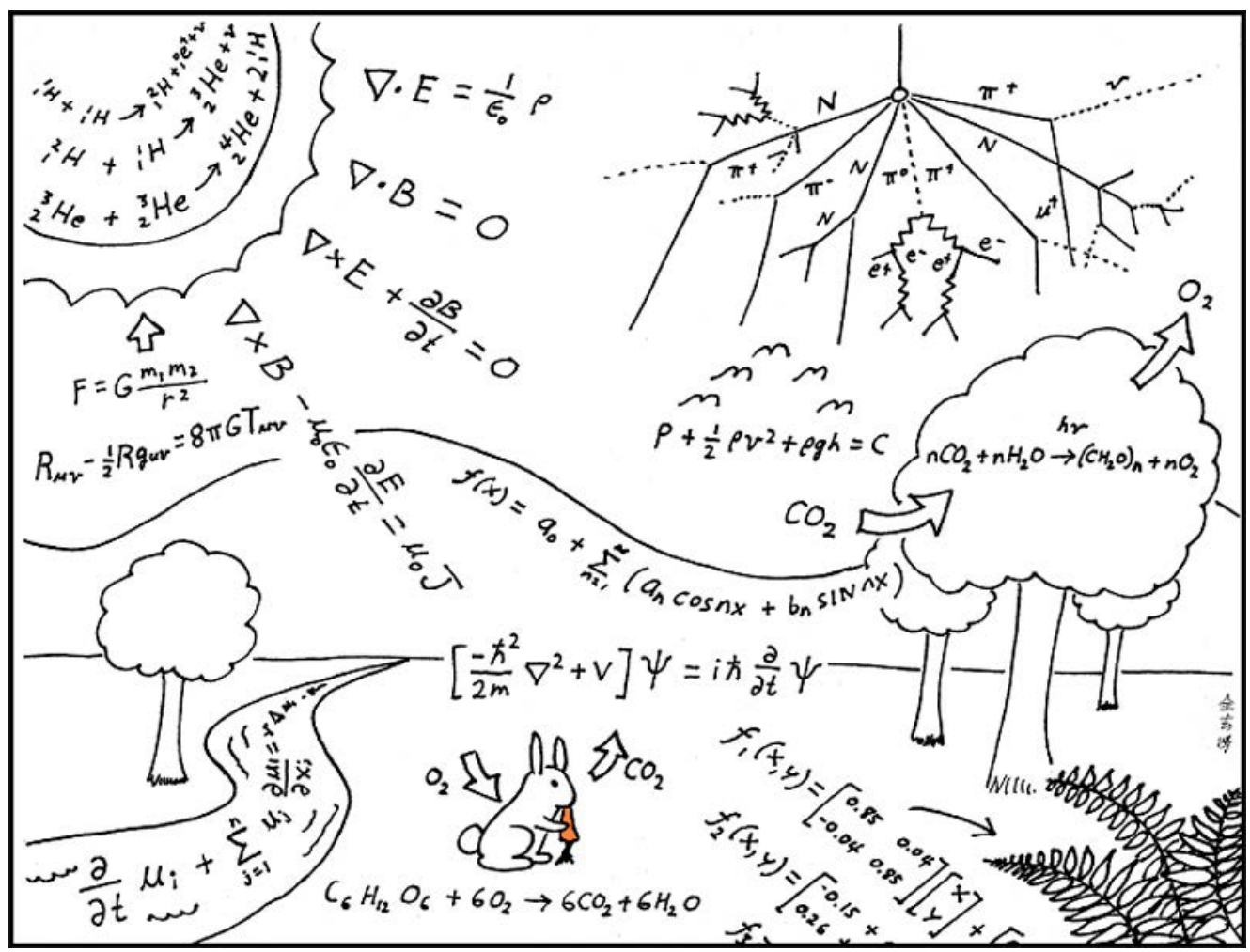

Fonte: Abstruse Goose (2019). ${ }^{4}$

Portanto, já que a criatividade parece residir no âmago da atividade científica, seja qual for, esse não parece o termo mais correto para designar tal movimento. De qualquer forma, feita essa observação, cabe agora abordar de que forma a específica interação entre Arte e Arqueologia que, definitivamente, parecem tender espontaneamente para a construção de um diálogo, pode ser benéfica para a nossa disciplina.

\section{Arte, Artefato, Arqueologia}

Há uma intersecção entre os dois campos que faz com que o diálogo entre Arqueologia e Arte seja possivel, poderiamos até dizer, inevitável.
Afinal, por mais que a Arqueologia tenha buscado refúgio por detrás das abstrações, na aparente intenção de dar ares de legitimidade a si mesma, nunca conseguiu deixar, também, de sujar as mãos ou de pisar na lama. Em contrapartida, a Arte, de igual forma, por mais que tenha privilegiado, em alguns momentos, o conceito, sempre careceu da sua extrapolação, sendo insuficiente ficar restrita à mera elaboração da ideia, senão que a sua efetiva execução. A situação que acabei de ilustrar, ela mesma, denota uma certa convergência entra as duas áreas. A suscetibilidade à implicação de uma conceitualização dual que reparte a vida, e que, em última instância, nos fragmenta.

\footnotetext{
4 Disponivel em: https://abstrusegoose.com/275. Acesso em: 5 nov. 2019 (editado).
} 


\section{4/15}

Oficina do historiador, Porto Alegre, v. 13, n. 1, p. 1-15, jan.-jun. 2020 | e-36634

Mas se as duas áreas apresentam intersecções, consequentemente, parece prudente afirmarmos que apresentam incongruências, posto que não são a mesma coisa. Essa etapa, portanto, é motivada por essa premissa. E está relacionada a uma preocupação que tenho - e que me parece historicamente justificável - sobre como a Arqueologia tende a importar conceitos, práticas sem o devido escrutínio. Isso parece um sintoma de um problema maior, que é a nossa falta de hábito de refletir sobre nós mesmos, nossa tendência em assumirmos que o que fazemos é uma coisa dada.

Assim, o que se deseja explorar aqui é de que maneira seria, então, não só prudente, mas oportuna uma aproximação à Arte, tendo em conta que não se objetiva advogar pela nossa conversão em artistas, mas, sim, pelo uso dela ao peso das necessidades da Arqueologia. Para tanto, antes de explorar os três pontos em que julgo tal aproximação benéfica nos termos expostos, eu gostaria de começar enfatizando uma incongruência fundamental: arqueólogos não são artistas.

\section{Sobre ser ou não ser (arqueólogo ou artista)}

Quando Simon Callery - consoante a diversas outras críticas - nos diz que "não vê necessidade em explicar as coisas, pois a explicação é uma forma de reduzir a experiência" (BAILEY, 2014, p. 234), que, por essa razão, "a Arqueologia parece ser sobre limitar interpretações, reduzir tudo à verdade e a fatos [enquanto a] Arte é mais rica quando trabalha por desentendimentos" (BAILEY, 2014, p. 235), nós não devemos nos esquecer de que quem está falando é um artista.

Figura 2 - Trench 10 [Trincheira 10], de Simon Callery

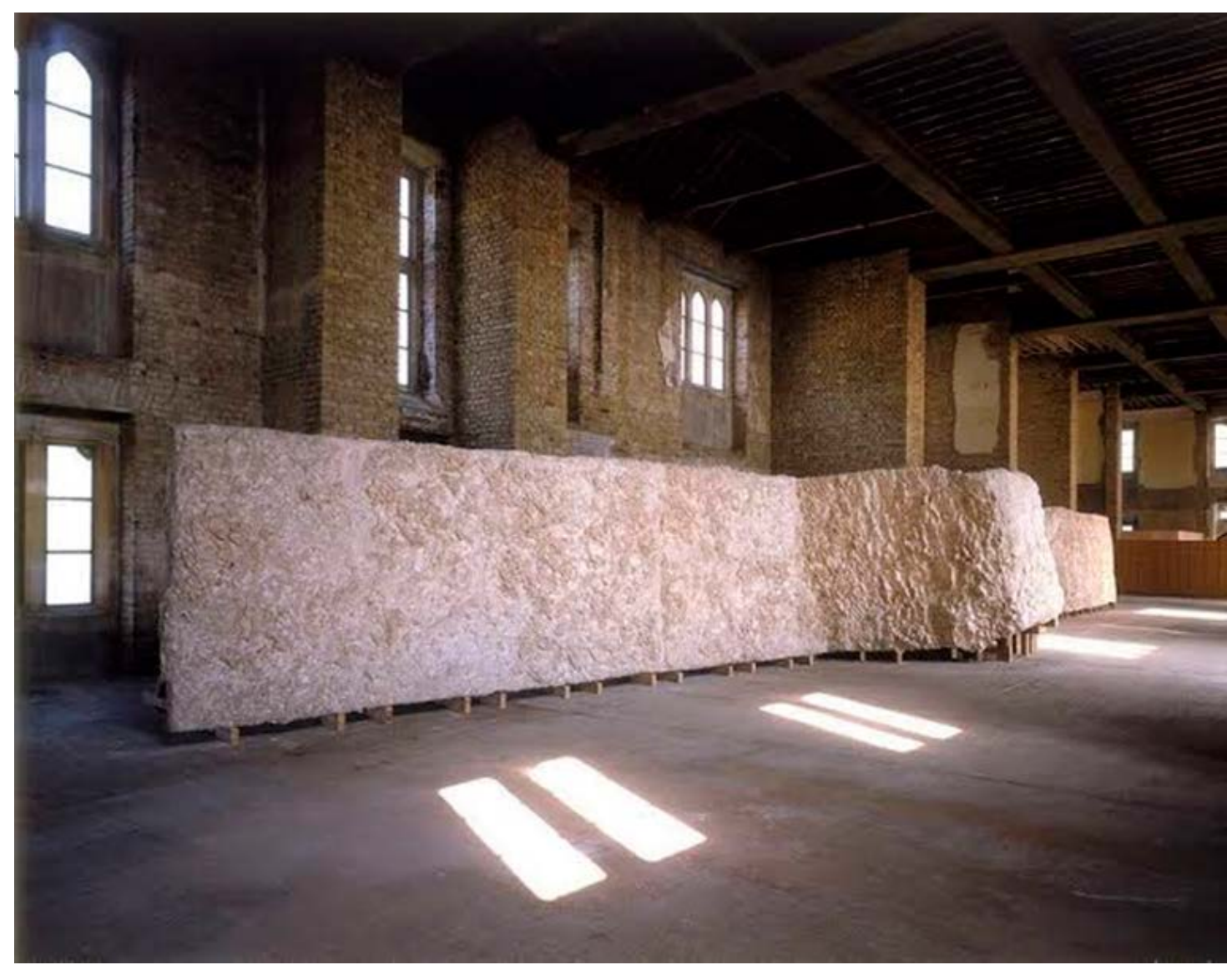

Fonte: Artimage (2000). ${ }^{5}$ 
Essa condição pressupõe a sujeição a uma circunstancialidade bem específica, muito diferente da nossa. Nós, arqueólogos, já demoramos muito tempo para assumir que a Arqueologia - e vale para a academia em geral - não existe alheia à sociedade, mas é parte dela, desempenhando um crucial papel social que nos investe de diversas responsabilidades inalienáveis. Portanto, há um bom tempo, já não temos mais desculpas para sermos levianos a ponto de continuarmos operando como se existíssemos em um plano distinto.

Nesse sentido, me parece que o trabalho do artista permite a ele uma atuação mais compromissada com as perspectivas pessoais do que a de um arqueólogo, pois, embora em maior ou menor medida toda atividade derive de uma motivação pessoal, a responsabilidade social do artista me parece, é de uma ordem diferente, que não o impede de extravasar, romper. Aliás, talvez até o estimule a isso. Já, por outro lado, o arqueólogo parece menos livre, embora ainda seja estimulada a experimentação, mas é a responsabilidade presumida que fundamenta o nosso fazer. Além disso, nós precisamos nos fazer compreender, seja entre nós mesmos, seja com a sociedade. Caso contrário, parece-me que nosso trabalho é em vão.

Em suma, a diferença fundamental entre nós a seguinte: o artista faz Arte; o arqueólogo, Arqueologia.

É nesse sentido que entendo ser providencial abordar criticamente essa aproximação - que é uma tendência iminente - e que entendo ser potencialmente fortuita para nós. Mas é preciso que façamos essas análises ao peso da nossa disciplina, ou seja, de acordo com as necessidades que a nossa atividade pressupõe, sem nos desvincularmos das nossas responsabilidades enquanto problematizadores do social. Além disso, que não passemos a contribuir, a partir de tal aproximação, para a diluição - meramente retórica, conscientemente ou não - e a consequente descaracterização da categoria arqueólogo que, em última instância, mascara as condições nem um pouco louváveis de surgimento, manutenção e desenvolvimento das atividades promovidas por nós (HUTCHINGS; LA SALLE, 2015).
Agora sim, é hora de entrar devidamente nos pontos em que podemos nos beneficiar dessa relação, sendo o primeiro deles no que diz respeito à epistemologia.

\section{Epistemologia combativa}

É preciso começar esta etapa destacando que não é objetivo aqui definir o que é a Arte, qual a sua natureza, por duas razões. Primeiro, parece consenso de que talvez nunca cheguemos a uma definição de Arte que acabe satisfazendo as problematizações de uma filosofia voltada a esse problema. Há, inclusive, sugestões mais contundentes como a de Morris Weitz de que a "Arte, como a lógica do conceito demonstra, não possui um rol de propriedades necessárias e suficientes, portanto, uma teoria dela é logicamente impossivel e não meramente factualmente dificil" (WEITZ, 1956, p. 28). Segundo, como já afirmei aqui, este artigo possui um foco na Arqueologia, nos arqueólogos; não na Arte, nos artistas. Portanto, parece contraproducente desenvolver mais essa questão. O que se pretende abordar, no entanto, é um entendimento, dentre vários - representativista, formalista, institucional - de Arte que seja fortuito para o desenvolvimento de uma Arqueologia mais pertinente.

Como mencionei no começo deste artigo, a dita virada criativa na Arqueologia tem despontado no momento em que os paradigmas teóricos mais tradicionais da disciplina começam a ser criticados por perspectivas que podemos considerar, de certa forma, contramodernas (THOMAS, 2004, p. 223-224). São elaborações que começam a colocar em xeque a dualidade humanista, a primazia da discursividade, o tempo linear, o sujeito-universal (BAILEY, 2014, p. 248). E essa concomitância não se dá por acaso. A busca por alternativas às formas tradicionais de produção de conhecimento se dá, justamente, para satisfazer os problemas que tais contestações pressupõem. Afinal, parece prudente pensar que, pelo menos em um primeiro momento, não seria muito produtivo abordarmos questões contramodernas meramente construindo narrativas como sempre fizemos. 
Por isso, parece razoável que essa busca pela Arte - não como mera inspiração como muitos colegas fazem (BAILEY, 2014, p. 235), mas como fundamentação - aconteça. E a Arte é o caminho a ser seguido, pelo menos agora, pois há uma grande intersecção entre ela e a Arqueologia: apesar dos pesares, das inconveniências conjecturais que nos afetaram e ainda nos afetam, ambas lidam com a nossa relação com o mundo material. ${ }^{6}$

Exposto isso, dentre as definições de Arte, há uma tendência que parece ser extremamente proficua para as aspirações atuais da Arqueologia, que é recorrer à sua conceitualização mais evidente, talvez, como aponta Collingwood, a Arte como a atividade de exprimir emoções (COLLINGWOOD, 2009, p. 43, 52). De outra maneira, podemos também seguir a sugestão de John Dewey e colocarmos a questão da seguinte forma: trata-se de uma experiência estética, ou seja, uma experiência singular qualitativamente vivenciada, que a destaca e a qualifica em oposição à mera experiência de estar jogado no mundo.

O processo da Arte em produção relaciona-se organicamente com o estético na percepção [...]. Até ficar perceptualmente satisfeito com o que faz, o artista continua a moldar e remoldar. O fazer chega ao fim quando seu resultado é vivenciado como bom - e essa experiência não vem por um mero julgamento intelectual externo, mas na percepção direta. $\mathrm{O}$ artista, comparado a seus semelhantes, é alguém não apenas especialmente dotado de poderes de execução, mas também de uma sensibilidade inusitada às qualidades das coisas. Essa sensibilidade também orienta seus atos e criações (DEWEY, 2010, p. 131).

Uma aproximação a tal entendimento de Arte é benéfica à Arqueologia pois oferece uma alternativa para combatermos uma epistemologia enraizada nos entendimentos da modernidade. Ela combate a desmaterialização do mundo promovida pelo dualismo humanista e pela discursividade, uma vez que tal entendimento pressupõe uma experiência, que implica a irredutibilidade da nossa relação com o mundo englobante, reconhecendo a sua integridade, em detrimento da sua abstração, que é vertical e impositiva. Também combate a temporalidade linear pois as coisas, inevitavelmente, escapam da purificação temporal promovida por tal ideologia. De igual forma, combate o esquecimento ao oferecer novas perspectivas sobre a problematização da nossa relação com o mundo, de modo que seja possível colocar a memória material - que deveria ser nossa especialidade enquanto arqueólogos, como Lynn Meskell defende (MESKELL, 2004, p. 62) - como elemento central da nossa problematização em detrimento das abstrações do historicismo. Além disso, ainda possibilita colocarmos em xeque a universalização da experiência, promovida pela construção de uma ideologia homogeneizante, uma vez que uma experiência qualquer pressupõe um corpo. Logo, ao materializarmos as suas condições, diluímos o sujeito-universal - denunciado por Sandra Harding (HARDING, 1993, p. 7) -, pois, ele pressupõe uma experiência-universal, e, ao levarmos em conta a contingencialidade das condições em que elas ocorrem, denunciamos seu caráter singular.

\section{Retórica arqueológica}

Uma aproximação à Arte nestes termos também nos oferece uma alternativa de explorarmos melhor as nossas capacidades. Se ao longo dos últimos séculos temos nos ocupado em construir narrativas sobre o passado, hoje, parece cada vez mais urgente que comecemos a oferecer alternativas ao volume sufocante de informações a que estamos sujeitos. E a nossa afinidade na lida com as coisas parece exigir que tomemos essa atitude.

Não esqueçamos que nós somos capacitados, também, pela nossa extensa história lidando com o mundo material, pela relação íntima que nós desenvolvemos com as coisas da vida cotidiana. Nesse aspecto, a Arqueologia oferece um potencial de resgatar as coisas, e ao propor uma alternativa às diversas narrativas sobre a vida social, traz consigo a distinta "vantagem de resultar menos na saturação da memória", como 
destaca Alfredo González-Ruibal (2008, p. 250).

Pois é preciso destacar que não se assume aqui que exprimir uma emoção - um sentimento - qualquer seja equivalente à sua descrição. As experiências são únicas e de outra ordem. O que a descrição acaba por fazer é reduzir a qualidade da experiência para as capacidades explicativas que os signos oferecem. Em certa medida, o que ocorre é uma descrição que só se efetiva no momento em que descaracteriza seu referencial.

A razão por que a descrição, ao invés de ajudar à expressão, acaba de facto por prejudicá-la está no facto de a descrição generalizar. Ao descrevermos uma coisa, estamos a designá-la como uma coisa pertencente a tal e tal espécie: estamos a submetê-la a um conceito, a classificá-la. A expressão, pelo contrário, individualiza. A raiva que eu sinto, aqui e agora, em relação a uma certa pessoa e devido a uma certa causa, é sem dúvida uma forma de raiva e ao descrevê-la como raiva estamos a afirmar uma verdade sobre ela. Mas trata -se de muito mais do que uma simples raiva, é uma raiva peculiar, muito diferente de todas as raivas que senti antes, e provavelmente muito diferente de todas as raivas que virei a sentir (COLLINGWOOD, 2009, p. 46).

Nesse sentido que se defende a possibilidade de que a Arqueologia esteja apta a desenvolver maneiras de articularmos a materialidade à vida social de modo de uma maneira relevante e única. A nossa atividade deriva dessa condição necessário, de estarmos no mundo. Nós não estudamos as pessoas por detrás das coisas, tão pouco nos limitamos ao fetichismo dos fragmentos, nós nos dedicamos a estudar a vida social a partir do mundo sensivel.

É possivel que estejamos, ao defendermos isso, sujeitos a um criticismo que nos jogue à margem da academia, afinal, ela está substanciada na "atividade intelectual" per se, embora isso não configure novidade na nossa inserção nos meios acadêmicos (OLSEN, 2016, p. 291). No entanto, quanto a isso, cabem duas manifestações. A primeira delas diz respeito ao fato de que defendo, como já mencionei, o reconhecimento das condições - nossas condições - de ação. Somos arqueólogos e nossa atividade está sujeita a determinadas incumbências, que dificilmente oferecem oportunidades para o desenvolvimento de atividades de natureza semelhante às que se defende aqui. Cabe a nós, portanto, elaborarmos alternativas para que isso aconteça. A segunda diz respeito à ideia de que, talvez por se tratar de uma limitação decorrente do modo como a informação circula nos meios acadêmicos, a linguagem tem a primazia sobre a racionalidade. E, quando argumentei que a linguagem não é capaz de dar conta da experiência, talvez eu a tenha reforçado caso o leitor tenha a trazido consigo. No entanto, cabe aqui, então, desfazer o imbróglio e dizer que concordo com o raciocínio de Susanne Langer sobre essa questão.

\begin{abstract}
Existe, entretanto, uma porção da realidade que é bem inacessivel à influência formativa da linguagem: trata-se do chamado reino da experiência interna, a vida de perceber e sentir. A razão pela qual a linguagem é tão impotente aqui não é, como muitos supõe, por uma pretensa irracionalidade do sentimento e da emoção; pelo contrário, eles aparentam ser irracionais pois a linguagem não é o suficiente para torna-los concebiveis, e muitas pessoas não conseguem conceber nada sem o desencadeamento lógico das palavras [...] Portanto, as palavras pelas quais nós nos referimos a sentimentos apenas nomeiam de maneira bem genérica tipos de experiências internas - excitação, calma, felicidade, sofrimento, amor. ódio, etc. Mas não há linguagem para descrever como felicidades diferem, por vezes radicalmente, umas das outras. $A$ verdadeira natureza dos sentimentos é algo que a linguagem como tal - um simbolismo discursivo - não consegue conceber (LANGER, 1966, p. 8-9).
\end{abstract}

\section{Extroversão e sociabilização}

Como coloquei no início, a diferença fundamental entre nós e os artistas é que nós fazemos Arqueologia. Isso pressupõe a ideia de que estamos inseridos em uma comunidade majoritariamente discursiva e que, também em decorrência disso, acaba desenvolvendo um aparto linguístico que a distingue e a isola. Todas as nossas atividades acabam sendo, em maior ou menor grau, condicionadas à limitação da discursividade.

Portanto, não configura novidade acusações de que a atividade acadêmica é enfadonha, aliás, quantas pessoas nós conhecemos que preferem 
estar em campo do que escrevendo relatórios ou artigos? Tampouco a ideia de que a nossa discursividade nos isola, não só pela restrição dos espaços por onde a informação circula, mas pelos códigos que usamos para descrever e explicar nossos objetos e problemas de pesquisa.

Materialidade, dicotomia, ideotécnico, signo, ontologia, burguesia, processo deposicional, fenomenologia, funcionalismo, percutor, fase, fitólito, patrimônio, semiologia, sincretismo, antropomorfo, zoólito, contentor, análise diacrítica, etnicidade, capitalismo, difusionismo, feminismo, transect, radiocarbono, perspectivismo, antropoceno, paleografia, anacronismo, dialética, idealismo, modernidade, cognição, identidade, estratigrafia, decolonial, petroglifo, brunidura, tradição, ungulado, survey, extrassomático, hermenêutica, historicismo, espectrometria, agência.

Nós estamos sujeitos a esse sistema, é verdade. A produção científica foi elaborada e se consolidou nesses moldes. Agora, isso não significa dizer que temos que nos limitar a essa situação. Se nós podemos - e nós, talvez mais do que ninguém, podemos - articular nossas ideias e nossas problematizações para fora das paredes da academia, isso acaba se tornando uma obrigação ética. E nós não devemos nos limitar à presunção de que os não acadêmicos, no caso, os não arqueólogos, não estejam propriamente municiados de modo que a comunicação seja presumida inócua. Pois, como diz o rapper Criolo, "cada maloqueiro tem um saber empírico" (CRIOLO, 2014).

Se a Arte não for uma espécie de ofício, mas antes a expressão da emoção, esta diferença de natureza entre artista e público desaparece. Isto porque o artista tem um público apenas na medida em que as pessoas ouvem a sua expressão e compreendem aquilo que ele diz. Ora, se uma pessoa diz algo como forma de exprimir o que lhe vai na mente e uma outra pessoa escuta e compreende o que ela diz, o ouvinte que o compreende tem essa mesma coisa na cabeça. Não precisamos de levantar aqui a questão de saber se ele a teria mesmo que a primeira pessoa não tivesse falado. Seja qual for a resposta a esta questão, aquilo que acabamos de dizer mantém-se igualmente certo (COLLINGWOOD, 2009, p. 51).
Assim, se nós nos permitirmos à elaboração de experiências estéticas enquanto complemento à discursividade científica, poderemos, ao menos, promover a socialização das nossas problemáticas e nos tornarmos mais arqueólogos.

\section{É preciso continuar fazendo Arte}

Para ilustrar o que venho expondo até aqui, resolvi trazer três exemplos de atividades promovidas por arqueólogas que entendo se enquadrarem nas premissas que levantei aqui. Começo trazendo o exemplo de Beatriz Thiesen et al. (2014), que desenvolveram uma instalação, Vestigios de uma Ausência, com o intuito de problematizar a percepção que a população da cidade do Rio Grande, RS, tem em relação ao período da ditadura civil-militar. A instalação era composta de cinco ambientes distintos, que formavam uma espécie de percurso. "Entrada", consistindo na recepção, onde constava o símbolo da atividade, um pau de arara e onde se pegava um nome, dentre tantos outros, em um pedaço de papel; "Quarto escuro", ambiente em que a pessoa ficava só e exposta a sons - que remetiam à tortura e a discursos de generais da época e à narração de jogos da Copa do Mundo de 1970 enquanto na parede eram projetadas imagens que remetiam à tortura; "Sala dos Rostos", ambiente silencioso e iluminado onde viam-se os rostos e as informações pessoais, data de desaparecimento, de sessenta e quatro brasileiros, onde era possivel buscar, em um daqueles rostos, o nome retirado no começo do trajeto (Figura 3); "Quarto da Ausência", a reprodução de um quarto vazio, que remente à época, e a uma pessoa que nunca mais voltou, com referências de discos, faixas e símbolos comumente associados à juventude e à quem se oporia ao regime; "Mural de Escritos", por fim, onde o ambiente revestido de papel pardo oferecia uma oportunidade para que as pessoas deixassem suas mensagens - e lessem as de outras pessoas - enquanto, ao fundo, ouviam-se canções de artistas como Chico Buarque e Milton Nascimento (Figura 4). 
Figura 3 - Imagem projetada na Sala dos Rostos. Foto: Célia Maria Pereira, 2014

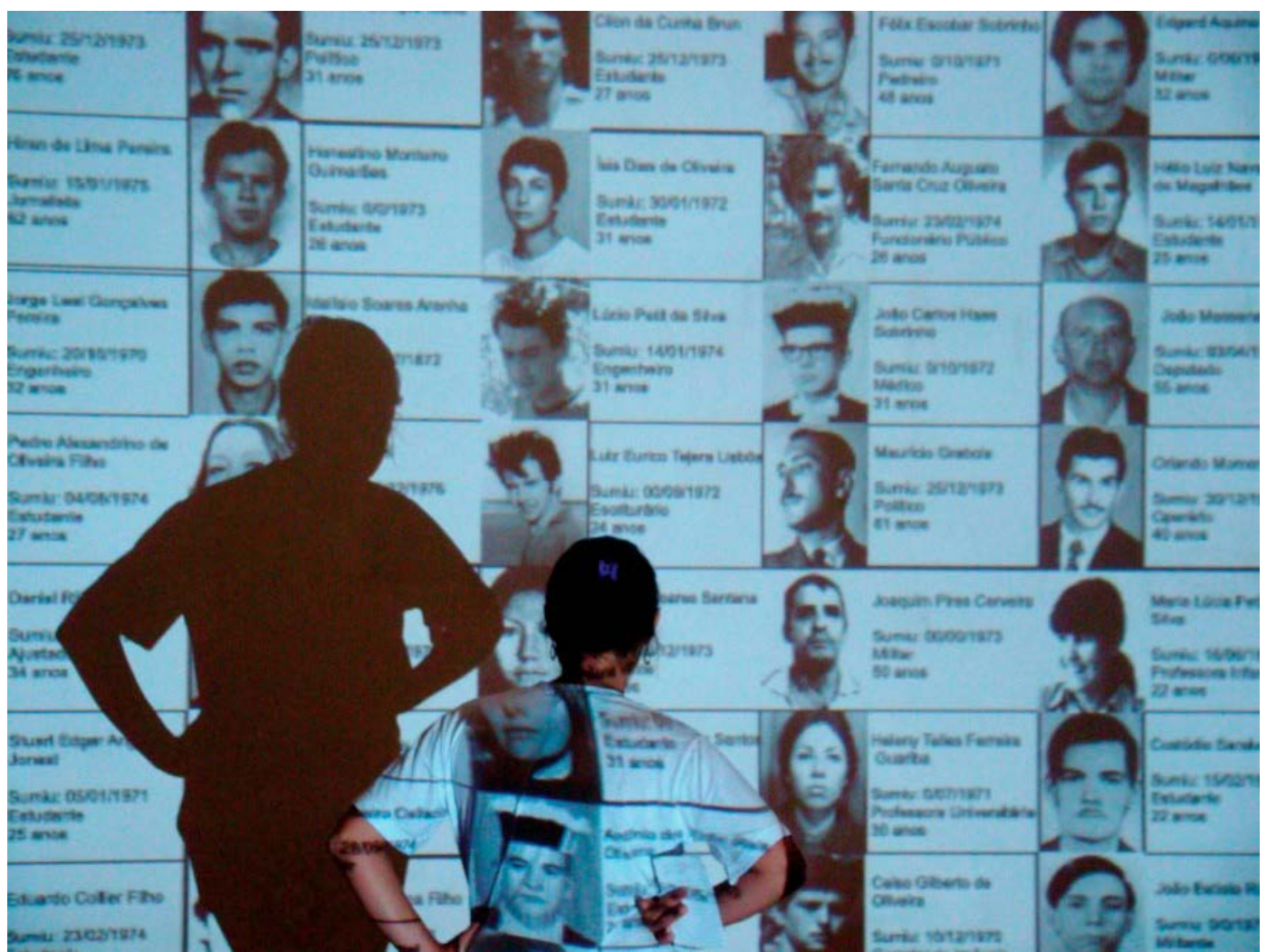

Fonte: THIESEN et al., 2014, p. 243

Figura 4 - Visita de estudantes

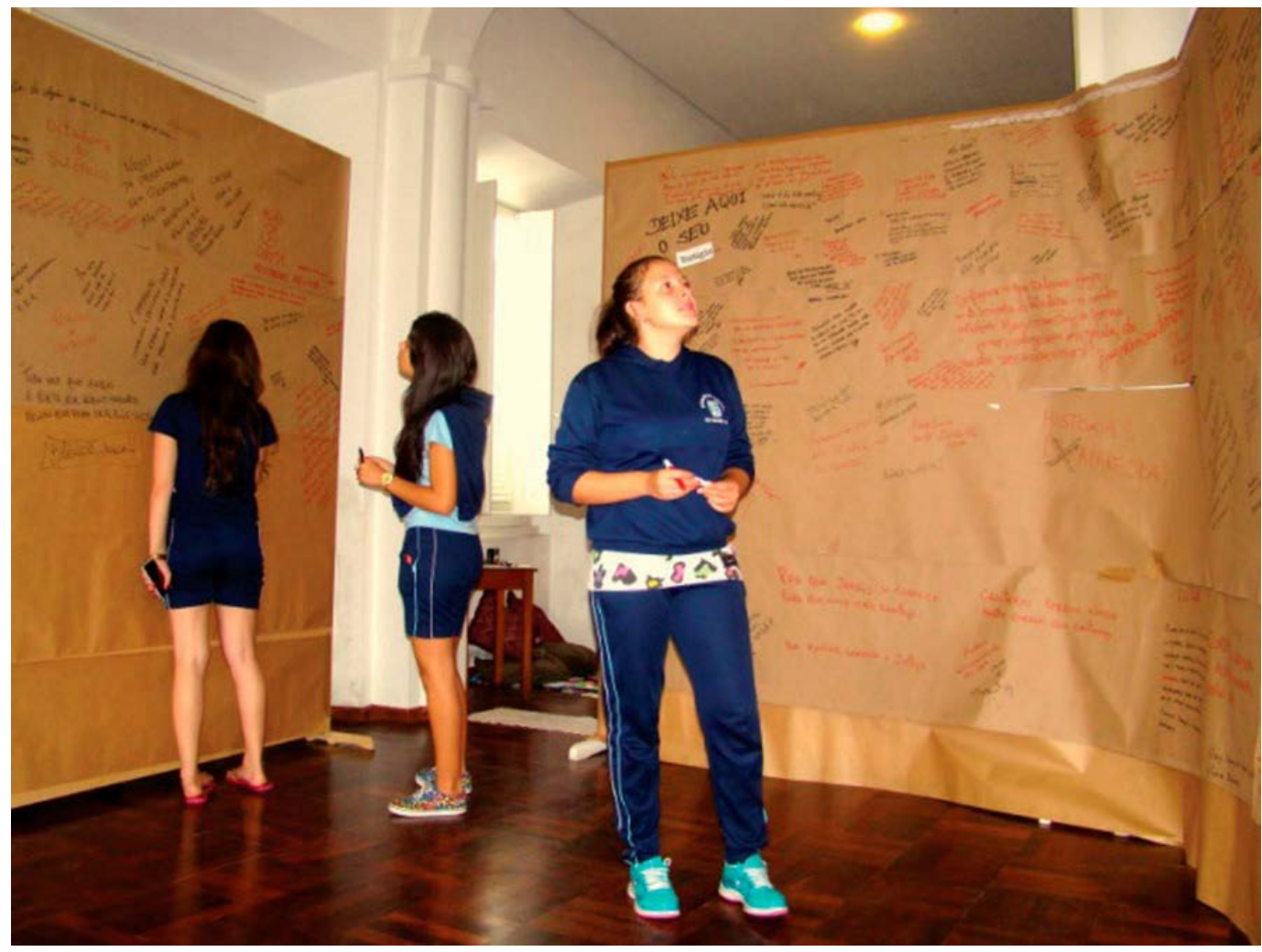

Fonte: THIESEN, et al., 2014, p. 246. Foto: Célia Maria Pereira, 2014. 
Em suma, o propósito é o de promover uma articulação entre a experiência das pessoas com as sensações que eram comuns à época. Denunciar os atos horriveis praticados pelo Estado brasileiro apenas a partir da substantivação da experiência fomentada por ele - tortura - não é o suficiente. Reduz, simplifica e desqualifica os horrores produzidos. A maneira mais lógica é, justamente, a de buscar uma outra racionalidade que fuja aos perigos e as amenizações impostas pela discursividade. Com a palavra, os autores.

O visitante ouve, sente cheiros, percebe cores - preto, branco, vermelho - que em alguns momentos estão presentes juntas, em outros, isoladas, como na sala escura, onde sons simultâneos ocorrem (polifonia). As cores, os sons, as imagens e os trajetos conduzem a percepções e a sensações, nos levando há um tempo que - mesmo não vivido -, através do simulacro, experimentamos. A instalação cria uma narrativa, articulando fatos ocorridos durante o regime ditatorial brasileiro, que resultou entre tantos sofrimentos, no desaparecimento de pessoas que a ele se opuseram. E nesse acontecidos, "personagens, objetos e lugares [atribuem] uma lógica sequencial e ritmica para compartilhá-lo com outras pessoas" (GLOSSÁRIO ..., 2010: 11) (THIESEN et al., 2014, p. 238).

Um segundo exemplo trata-se do trabalho de Yasmin Silva (2018), Arqueologia da Geribanda, onde o processo de revitalização da Praça Tamandaré, também na cidade do Rio Grande, RS, que, conforme o discurso oficial, buscava estabelecer melhorias para a população local, mas não passava de uma tentativa do poder público de impor uma espécie de ordem moral. A Praça Tamandaré, nesse sentido, é um lugar emblemático. No século 19, o espaço era conhecido como Geribanda - sinônimo de "descompostura" (SILVA, 2018, p. 21) -, um dos poucos locais da cidade com acesso à agua potável, e era frequentado por grupos sociais marginalizados. Com o tempo, sofreu processos de embelezamentos, recebeu os restos mortais de Bento Gonçalves e mudou de nome, Praça Tamandaré, para homenagear o patrono da Marinha Brasileira, rio-grandino. Mas, apesar dos esforços do poder público local, a Praça sempre acabou sendo reapropriada pelos grupos que ele tentava excluir do espaço. Nesse caso mais recente, Silva notou que, parte da nova proposta de higienização da Praça consistia na retirada das taquaras - bambus -, por, aparentemente, questões de segurança. No entanto, como a autora nos coloca, as taquaras estão intimamente associadas às práticas das religiões de matriz africana (Figura 5) e, ainda, que a praça era recorrente utilizada como espaço para práticas desses ritos (SILVA, 2018, p. 6268). Com o propósito de chamar a atenção para esse fato, realizou intervenções na Praça, com a instalação de mensagens nas taquaras - como se estivessem falando conosco -, alertando a população que frequenta sobre a sua retirada, bem como indicando as alegações do poder público local para tal ação (Figura 6).

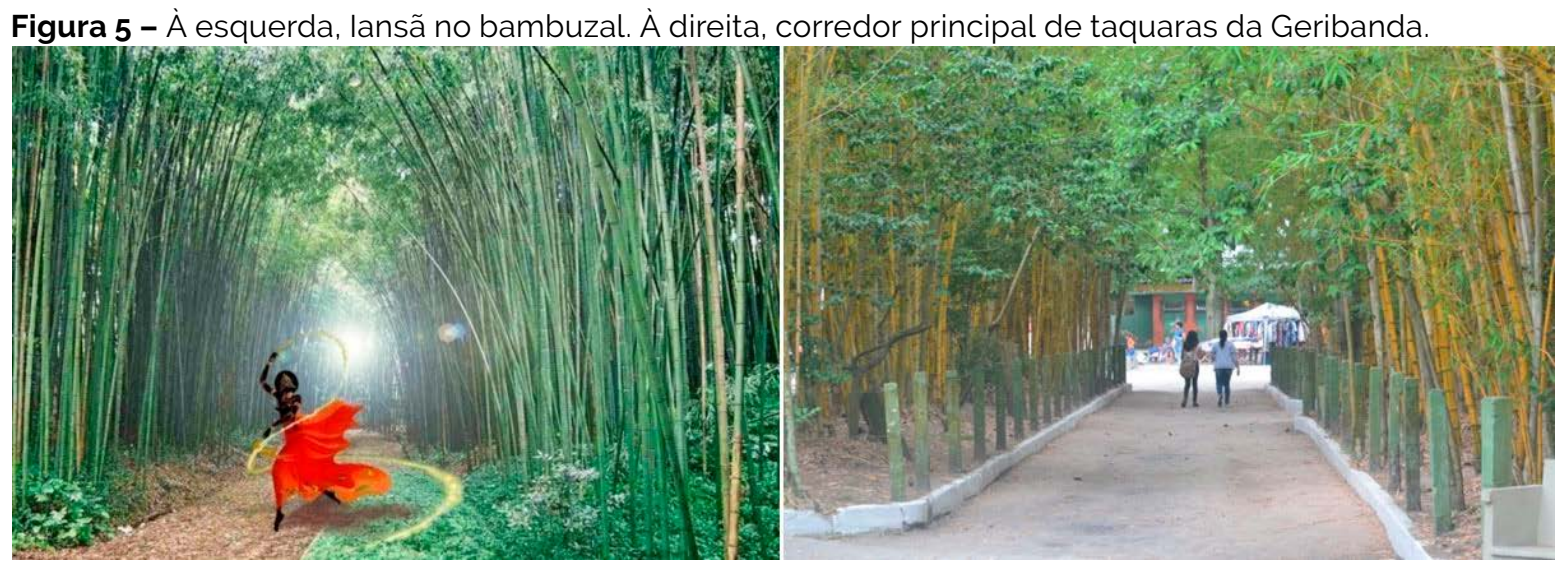

Fonte: SILVA, 2018, p. 64. Editado. 
Figura 6 - O dia em que as taquaras falaram

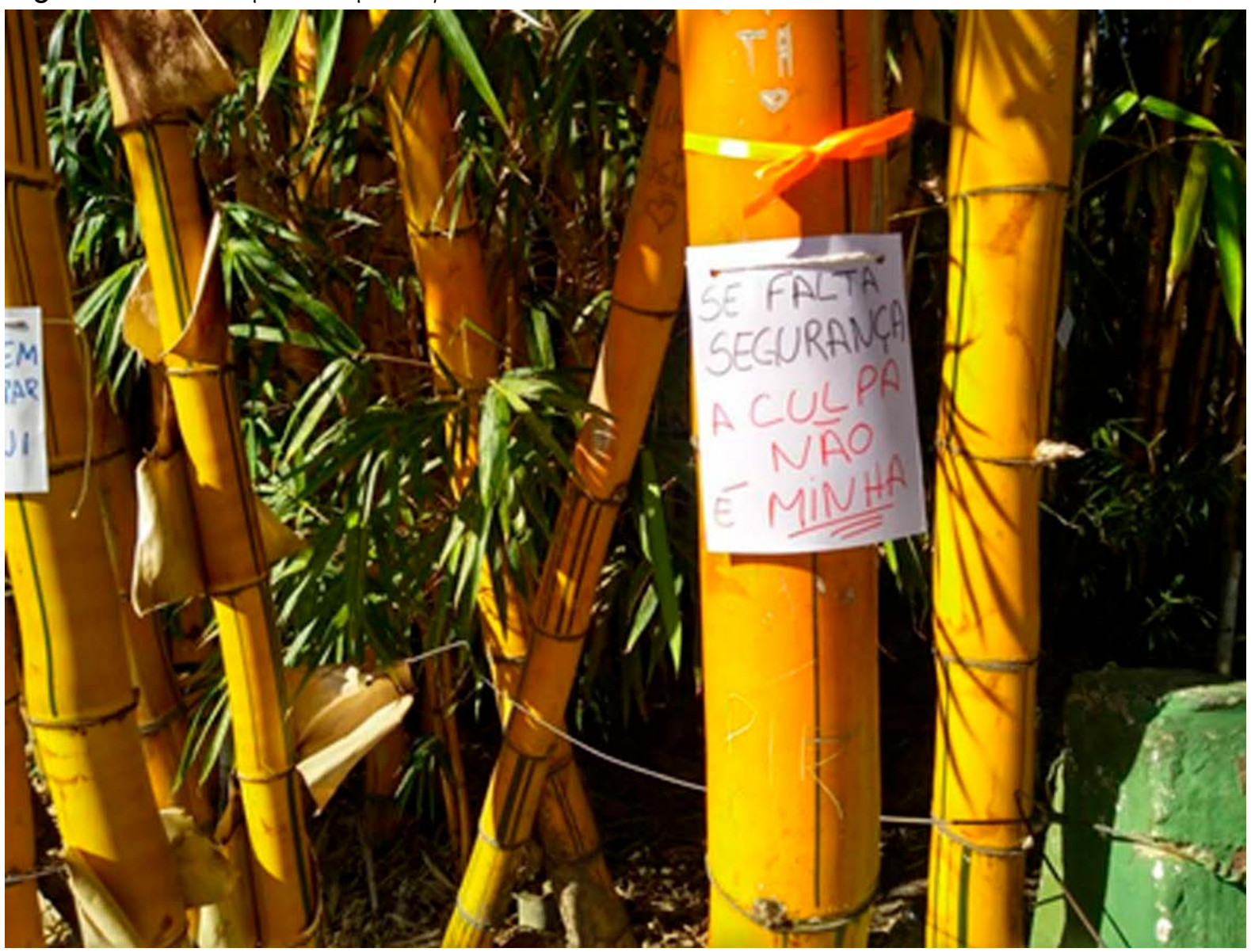

Fonte: SILVA, 2018, p. 78.

As boas intenções de revitalizar a Praça de novo, trazem à tona, no fundo, práticas excludentes que, através de um pensamento higienista, transformaram a Geribanda num lugar onde pessoas bem incluidas na sociedade iam passear com suas famílias. Acredito que os projetos arquitetônicos não são inocentes, pois são feitos pra grupos especíicos. Por exemplo, retiraram as pessoas da Geribanda e a transformaram em um espaço fabuloso, com inspirações de outros paises, construindo, portanto, uma praça pra elite. A mesma se apropria dela por um momento, porém pessoas comuns ressignificam a Praça, mudando o uso ao qual ela foi construída.

Compreendi que todos os discursos (do passado-presente) silenciam e excluem usuários e usuárias que frequentam a Praça diariamente. Entretanto, eu não quero bater na tecla de uma praça de pessoas excluidas ou entender a mesma como um lugar de exclusão. Chega de exclusão. A Praça é nossa. Se as políticas públicas, recheadas de "qualificações" do espaço, geram o silenciamento e apagamento de pessoas e suas memórias, então que gritemos. A partir disso, concebo a Praça como um espaço de resistência (SILVA, 2018, p. 80-81, grifo da autora).

O último exemplo trata-se do vídeo arqueológico de Vanessa Costa intitulado Evocando Paisagens (COSTA, 2019). Nele, a autora nos apresenta a Mestra Griô Sirley Amaro (Figura 7), que conduz a narrativa do vídeo ao percorrer as ruas de Pelotas, RS. Enquanto o faz, Sirley, em primeiro plano, narra a paisagem do seu tempo, as coisas como não são mais, alimentada pelas memórias que decorrem da sua presença em fluxo pelas ruas da cidade. O vídeo não apresenta uma edição de som que privilegie a narração em detrimento do som ambiente. Enquanto Sirley fala, automóveis passam, ouve-se buzinas, outros transeuntes passando. No entanto, há um cuidado com a edição das imagens, pois, conforme ela vai apontando determinados aspectos da paisagem que são elementos importantes na sua narrativa (Figura 8), há um breve corte, e, quanto 


\section{$12 / 15$}

Oficina do historiador, Porto Alegre, v. 13, n. 1, p. 1-15, jan.-jun. 2020 | e-36634

continuamos a ouvir Sirley e a rua, enxergamos aqueles aspectos da paisagem aos quais ela se refere e, então, o vídeo retoma seu fluxo. Este empreendimento é um excelente exemplo de como podemos acessar percepções do espaço que fogem das cartografias tradicionais. Não apenas isso, trabalhos dessa natureza nos permitem acessar uma materialidade que, de outra forma, continuaria inacessivel. A narração de Sirley enquanto caminha pelas ruas, é uma possibilidade de acesso a espaços que foram transformados tão legítima quanto cartas, plantas, relatórios e outras espécies de indicações indiretas. Também, representa uma oportunidade de problematizarmos a sincronia e a diacronia das paisagens, pois "paisagem" não é uma categoria estanque, e se a abordamos presumindo que sim, apenas o fazemos devido a limitações acadêmicas. A vida, lá fora, não para. As paisagens que existem são aquelas como das de Sirley. E nesse emaranhado de paisagens vividas, evidentemente, que umas são privilegiadas em detrimento das outras.

Figura 7 - A Mestra Griô Sirley Amaro

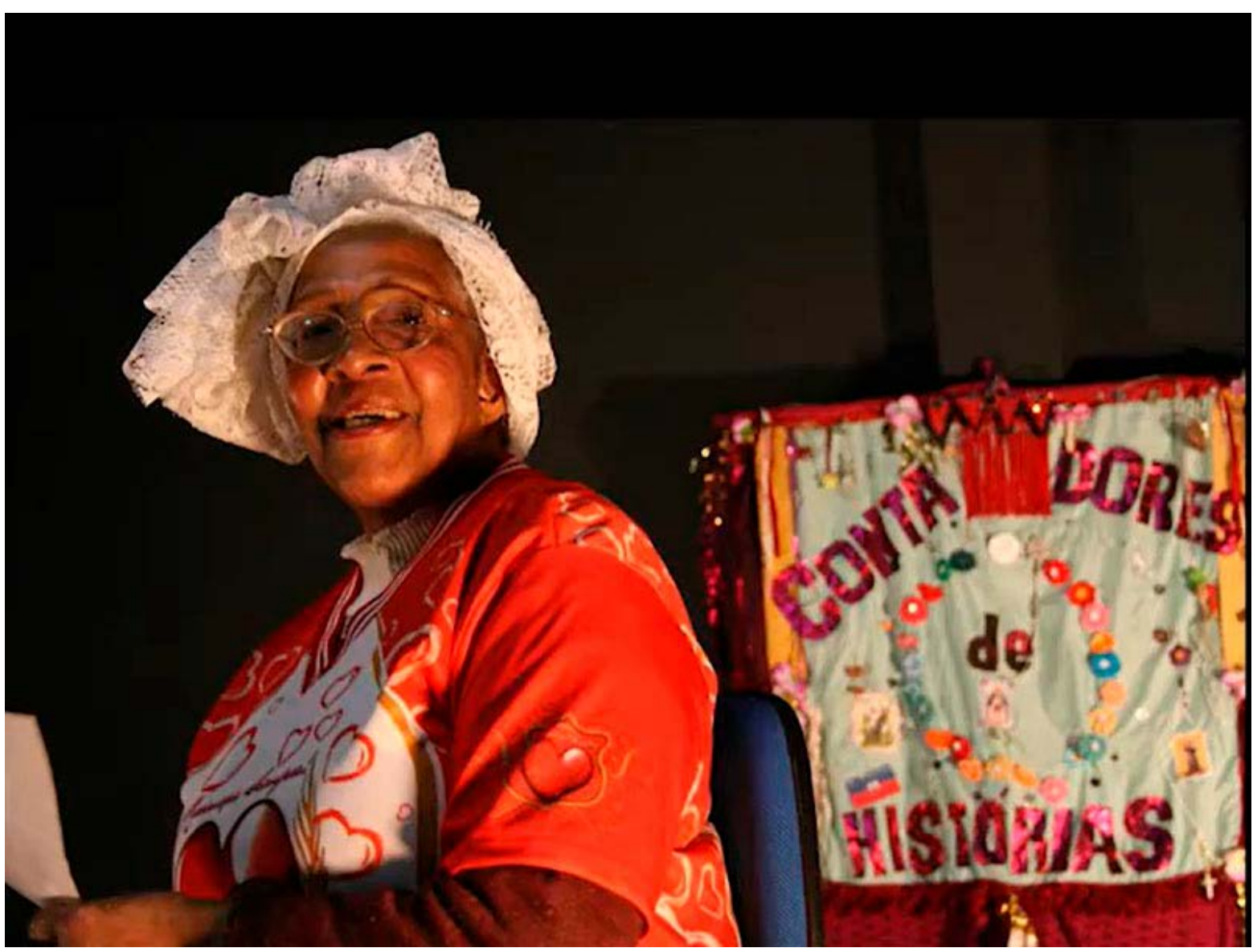

Fonte: Frame do filme de Costa (2019). 
Figura 8 - A Mestra Griô Sirley Amaro narrando seu passado

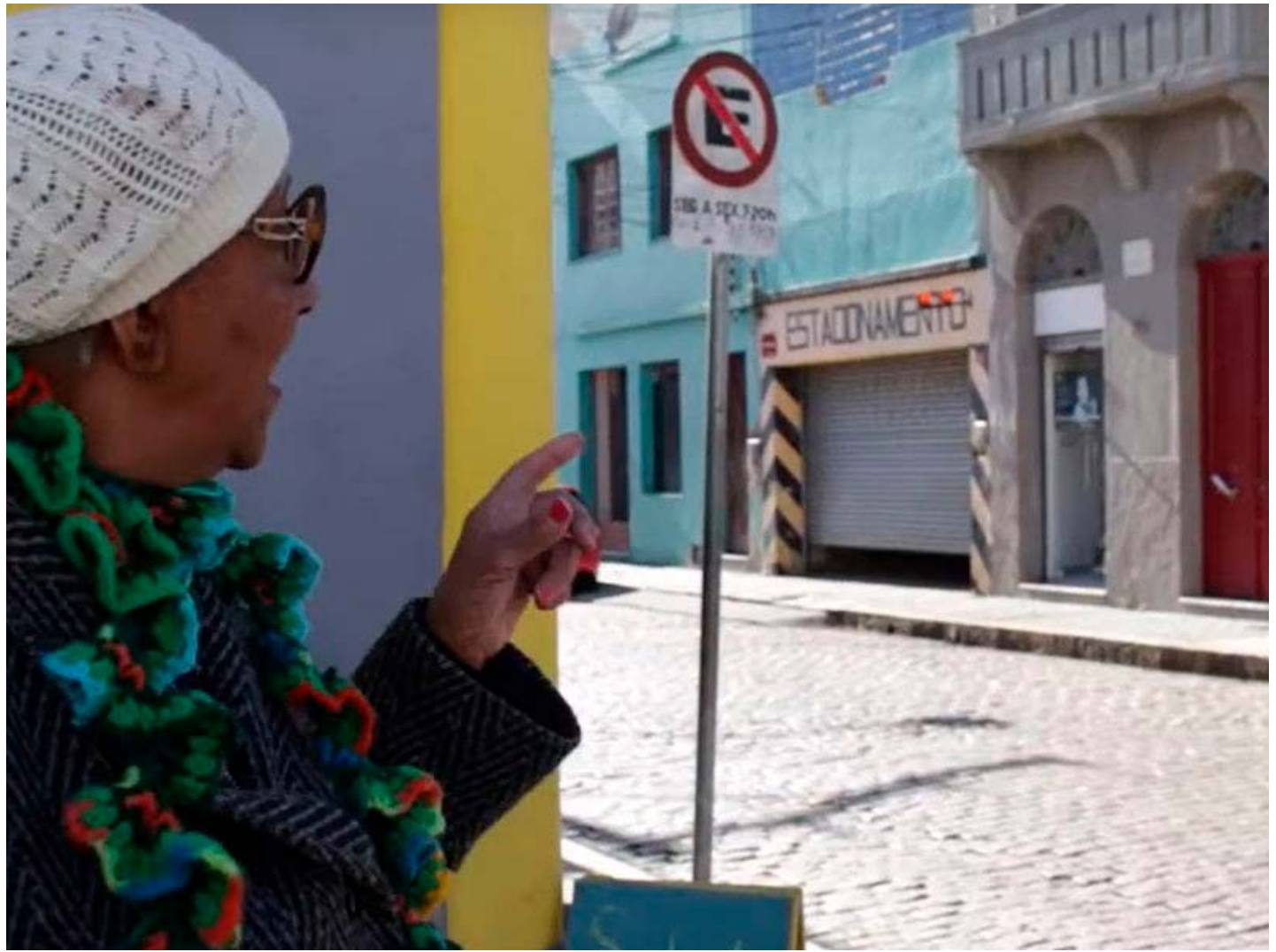

Fonte: Frame do filme de Costa (2019).

Parafraseando Agier (2015), la Arqueologia] reivindica o direito à paisagem pelos grupos que estão em processos de exclusão no contemporâneo da cidade. E, nesse sentido, é importante levar em conta que a situação de subalternidade em que eles se encontram no presente tem raizes não em um passado, mas em diferentes passados de opressão e, consequentemente, de "resistências cotidianas" - as táticas de Certeau (1994) -, de negociações e trocas, e que, não evocar esses passados é continuar silenciando-os.

O seu papel é produzir contra-narrativas a partir do reconhecimento dos patrimônios das comunidades, para trazer o sentido de representatividade aos(as) envolvidos(as). Construir, no presente, outros passados que não são aqueles dos "vultos da história" (homens brancos da elite, assumidamente heterossexuais, e cisgêneros), mas de grupos que subvertem, no cotidiano, a normatividade estabelecida por um ordenamento urbano que não pensa na sua pluralidade de ser e habitar, que lutam pelo seu direito à cidade (AGIER, 2015. p. 483) e, assim, desconstroem, de diversas formas, as fronteiras que lhes são impostas (COSTA, 2018, p. 25).

\section{Considerações finais}

Se nós presumimos que a Arte é algo da condição humana, a única hipótese de diferenciação plausivel entre um arqueólogo e um artista se dá no plano do ofício. E por ofício, me refiro ao desenvolvimento de conceitos, técnicas, habilidades peculiares que nos qualificam e, por consequência, nos inserem em determinado espaço da sociedade. Por sua vez, ao ocuparmos estes espaços, somos incumbidos de expectativas que correspondem ao nosso alocamento e que trazem consigo as respectivas responsabilidades ante nossa comunidade.

O objetivo do arqueólogo, então, é o de buscar na Arte, não meramente inspiração como se supõe de uma Etnoarqueologia (BAILEY, 2014, p. 238), mas desenvolver ainda mais nossa competência em abordar a vida material. Como diz Collingwood, a maior característica do que ele chama de "verdadeira expressão" é a "lucidez ou inteligibilidade" (COLLINGWOOD, 2009, p. 55). E 
é isso que nós devemos buscar. Nossa relação com o mundo não se limita à metáfora textual. Mas, nem por isso mesmo, caracteriza-se como irracional, apenas não aceita a redução da vida a signos como satisfatória. O que nós devemos buscar, então, é explorar essa inteligibilidade, pois aquele que "exprime algo torna-se ipso facto consciente daquilo que está a exprimir e torna possivel, aos outros bem como a si mesmo, a tomada de consciência daquilo que está a exprimir" (COLLINGWOOD, 2009, p. 55).

Nesse sentido, quando parafraseio Mário Quintana e digo que quem faz Arqueologia abre uma janela, afirmo em um duplo sentido. Diante das imposições da lógica moderna que nos sufoca e, em certa medida, nos desumaniza, fazer Arqueologia pode representar uma alternativa de lidarmos com a vida como ela é para além dessas limitações. Em um outro sentido, significa entender que, enquanto parte integrante desse sistema vigente - afinal, somos cria da modernidade e estamos inseridos dentro do aparato estatal - nós também somos o problema (HUTCHINGS; LA SALLE, 2015). Mas, para além de reconhecermos nossa condição, é preciso que mudemos. E entendo que "ethos arqueológico baseado na violência epistêmica pode ser superado por uma prática responsável, aberta, reflexiva e compromissada" (GNECCO, 2009 apud GONZÁLEZ-RUIBAL, 2016, p.3).

\section{Referências}

BAILEY, D. Art//Archaeology//Art: Letting-Go Beyond. In: RUSSEL, I. A.; COCHRANE, A. (ed.). Art and Archaeology: collaborations, conversations, criticisms. New York: Springer, 2014. p. 231-250. https://doi. org/10.1007/978-1-4614-8990-0_15

BHASKAR, R. The Blackwell Dictionary of Modern Social Thought. In: OUTHWAITE, W. (ed.). Ontology. 2. ed. Malden, Oxford, Victoria: Black Publishing, 2006. p. $442-443$.

COLLINGWOOD, R. G. A arte autêntica como expressão. In: MOURA, V. (ed.). Arte em teoria: uma antologia de estética. Braga: Universidade do Minho. Centro de Estudos Humanísticos (CEHUM), 2009. p. 39-58

COSTA, V. A. Arqueologia das Margens: pensando paisagens e fronteiras. Tessituras, Pelotas, v. 6, n. 1, p. 21-28, 2018.
COSTA, V. A. Evocando Paisagens: uma cartografia de memórias da Griô. 2019. 1 vídeo (10min40s). Disponível em: https://youtu.be/6957MblpVoM. Acesso em: 22 nov. de 2019.

CRIOLO. Esquiva da Esgrima. São Paulo: OLOKO RECORDS, 2014. Disponivel em https://open.spotify. com/track/2IWhlmeGgaRRupVnEJsQgZ?si. Acesso em: 22 nov. d 2019 .

DEWEY, J. Arte como experiência. São Paulo: Martins Fontes, 2010.

GONZÁLEZ-RUIBAL, A. Time to destroy. An archaeology of supermodernity. Current Anthropology, [S. l.], v. 49, n. 2, p. 247-279, 2008. https://doi. org/10.1086/526099

GONZÁLEZ-RUIBAL, A. Reclaiming Archaeology. In: GONZÁLEZ-RUIBAL, A. (ed.). Reclaiming archaeology. Beyond the tropes of modernity. New York: Routledge, 2016. p. 1-29. https://doi. org/10.4324/9780203068632.ch1

HARDING, S. A instabilidade das categorias analiticas na teoria feminista. Revista Estudos Feministas, Florianópolis, v. 1, n. 1, p. 7-31, 1993.

HUTCHINGS, R.; LA SALLE, M. Why Archaeologists Misrepresent Their Practice - A North American Perspective. Journal of Contemporary Archaeology, [S. l.], v. 2, n. 2, p. S11-S17, 2015. https://doi.org/10.1558/jca.v2i2.28206

ISAACSON, W. Einstein: sua vida, seu universo. São Paulo: Companhia das Letras, 2007.

LANGER, S. K. The Cultural Importance of the Arts The Journal of Aesthetic Education, [S. l.], v. 1, n. 1, p. 5-12, 1966.

MESKELL, L. Object Worlds in Ancient Egypt: material brographies past and present. Oxford, New York: Berg, 2004.

OLSEN, B. The return of what?. In: GONZÁLEZ-RUI$\mathrm{BAL}, \mathrm{A}$. (ed.). Reclaiming archaeology: beyond the tropes of modernity. New York: Routledge, 2016. p. 289-297. https://doi.org/10.4324/9780203068632.ch1

SILVA, Y. A. d. Arqueologia da Geribanda: (re)existências no passado-presente. Monografia de Conclusão de Curso (Bacharelado em Arqueologia) -- Rio Grande, Instituto de Ciências Humanas e da Informação, Universidade Federal do Rio Grande, 2018. https:// doi.org/10.5327/z2176-947820152614

THIESEN, B. et al. Vestigios de uma ausência: uma arqueologia da repressão. Revista de Arqueologia Pública, Campinas, v. 8, n. 10, p. 232-250, 2014. https:// doi.org/10.20396/rap.v8i2.8635659

THOMAS, A. et al. Beyond Art/Archaeology: research and practice after the "creative turn". Journal of Contemporary Archaeology, IS. L., v. 4, n. 2, p. 121-129, 2017.

THOMAS, J. Archaeology and modernity. London: Routledge, 2004.

WEITZ, M. The Role of Theory in Aesthetics. The Journal of Aesthetics and Art Criticism, IS. L.J, v. 15, n. 1, p. 22-35, 1956. 


\section{Endereço para correspondência}

Felipe Benites Tramasoli

Pontifícia Universidade Católica do Rio Grande do Sul

Avenida Ipiranga, 6681, Prédio 40

Partenon 90619-900

Porto Alegre, RS, Brasil

\section{Felipe Benites Tramasoli}

Doutorando em História pela Pontificia Universidade Católica do Rio Grande do Sul (PUCRS, Porto Alegre, RS, Brasil). 